\title{
Introduction
}

\section{PAUL MAHARG}

This edition of the journal contains papers from two BILETA conferences, namely those held at the University of Edinburgh (2001) and the Free University, Amsterdam (2002). Recently the Association changed its name from 'British and Irish Legal Educational Technology Association' to the 'British and Irish Law Education and Technology Association'. The change reflects what had been happening at the BILETA conferences over the last 17 years, namely a considerable widening of the scope and specialist depth of papers presented at conference.

This is of course symptomatic of the wider development of the field of law and ICT, and we can see this at work if we consult the substantial archives of BILETA conference papers, at http://www.bileta.ac.uk/pubs.html. This archive, unique in the field of law and IT, is a remarkable repository for those interested in the historical development of the field, and enables us to chart the developments within it. In the domain of legal educational technology, for instance, there is evidence of the early years of individual initiatives, the TLTP projects and their effects, the use of datasets in education, and the rise of the web as an educational medium. We can trace within the alluvium of papers the lineaments of legal educational theory, from programmed learning to instructional design, the effects of Al and the application of theory such as constructivism. What the archives also reveal is that, for well over a decade, interdisciplinary concerns have sat cheek by jowl in complementary or contrasting streams within the conference. In addition, panels have been formed on current concerns that draw together academics and practitioners to debate issues across a number of concerns. ${ }^{1}$

What is remarkable, above all, is that with very few exceptions in the field of law can there be said to be a conference that has such a range of multi-disciplinary roots and whichengages in interdisciplinary analysis and critique. To a degree, of course, a new field such as law and technology must of necessity bring together parts of older domains to constituteitself. But the marches of the law/ICT demesne have remained 'porous', in the sense that Boaventura de Sousa Santos uses the term when he describes law's project generally as one of 'porous legality or of legal porosity of multiple networks of legal orders forcing us toconstant transitions and trespassings'. ${ }^{2}$ It is one of the responsibilities of the BILETA executive to ensure that the conference retains this openness, and in so doing supports a tradition of interdisciplinary research and development that is probably without parallel in the field of law and IT in any other jurisdiction.

The range of peer-reviewed papers published here reflects such a porous and diverse approach. Indeed, despite their diversity, it would not be too presumptuous to claim that the papers in this volume are united by their common pursuit of this broadened vision of technology as a social phenomenon. Clark, Cho and Hoyle discuss the use of technology in dispute resolution, including applications such as online courts and ODR. They review the use made of current technologies and summarize the policy and regulation issues. One of the key issues is of course that of professional practice: will practitioners use the new technology, and if so, how? In the view of the authors, many of the problems currently associated with ODR will 'disappear once practitioners ... gain more experience in managing the technology and the processes'.

Similar conclusions are reached by Hörnle. She investigates in more detail the extent to which negotiation within legal practice is a highly individualized activity, one where personal presence, procedural flexibility and confidentiality is important to the outcome of the negotiation. She demonstrates that the slow uptake of ODR is due in part to the deficiencies of technology in supporting methods of negotiation, while noting that even in large-scale commercial arbitration, where use of ODR is lowest, 'some ODR techniques are already commonly used'. It is a situation, of course, that is common throughout the many implementations of ICT in legal practice: practitioners are more often willing to take small steps towards using new hardware or software, rather than abandoning wholesale their previous methods of working, and adopting new procedures.

Most universities in the UK are either considering the use of, or using, virtual learning environments. While there is much discussion and research on their development (see for example the substantial JISC site at www.jisc.ac.uk/mle/), there are few detailed examples of their use in law. Bloxham and Armitage describe a web-based virtual learning environ- ment, and the use to which it was put in a Law of Obligations course at Lancaster University. The feedback that they received on the implementation bears out much of the research and implementation literature on learning (particularly collaborative learning), communications and 
the Internet.

Internet regulation is a subject of concern to all web-users and policy-makers. In their paper, Cannataci and Bonnici address the complex issues of self-regulation within the transnational context of the Internet. They argue that self-regulation is capable of tran- scending the problems of jurisdiction and effective sanction, particularly in those areas of web activity where regulation is necessary but the incentive for statutory regulation is low. Regulation of domain names is one feature of Internet regulation and it is examined in some detail in Roos' article. Currently, the Swedish system allows for registration of domain names in the top-level domain, ie '.se' names. While preventing disputes over registration, the system's implementation has been criticized on a number of issues. Roos analyses these with examples, compares them to the systems of domain name registration operating in other jurisdictions, and outlines alternatives to the system.

Other regulatory issues are discussed by Sutter, and by Hosein, Tsiavos and Whitley. Sutter focuses on the need to control certain forms of Internet content, in particular obscenity, copyright infringement and defamation. He analyses the approaches taken in the UK and the USA, and suggests alternatives to the UK approach. Hosein, Tsiavos and Whitley discuss the extent to which a technology's architecture can regulate alongside moretraditional devices of regulation in the form of statutory intervention or market forces. They do so by presenting a critique of Lawrence Lessig's concept of 'code as law', arguing that such a view of a regulatory architecture serves to reify it. Using two case studies (peer-to-peer services and cryptography), they point out that there is no certainty that technology with a regulatory intent can be said to 'produce a particular behaviour; rather, it will affect it'.

Bromby, MacMillan and McKellar use a CommonKADS approach to the design of a smallscale system to evaluate eyewitness evidence. The system is based upon the set of rules outlined in R $\vee$ Turnbull, and in the article the authors outline their approach to three aspects of the system, namely the organization, the agent and the task models.

Finally, in the Current Developments section Muntjewerff gives notice of the HYPATIA project and its aims. She outlines the theoretical approach of the project and its specific project implementations.

The 18th annual BILETA conference was held in London, Monday 14 April to Tuesday 15 April 2003. The conference, entitled 'Controlling Information in the Online Environ- ment', was hosted by the Institute of Computer \& Communications Law of the Centre for Commercial Law Studies, Queen Mary, University of London, and the venue is the Maritime Greenwich Campus. $^{3}$

\section{Notes and References}

1 See for example the panel session at the 1999 conference at the College of Ripon and York St John-'Beyond Law as a System of Rules: Getting IT Right'.

2 B de Sousa Santos 'Law: a map of misreading' Journal of Law and Society Vol 14, p 279, 1987. See also B de Sousa Santos Toward a New Common Sense: Law, Science and Politics in the Paradigmatic Transition Routledge, London, 1995. For an interesting account of trespassing as a method of crossdisciplinary research and its consequences, see David P Ellerman Cultural Trespassing as a Way of Life: Essays in Philosophy, Economics and Mathematics Rowman andLittlefield, London, 1995.

3 http://www.gre.ac.uk/about/campus/maritime.htm. 